\title{
THE RELATION BETWEEN SOCIAL ACHIEVEMENT AND THE DEGREE OF IMPROVEMENT OF PARAPLEGIC PATIENTS IN THE REGION OF CRACOW *
}

By A. Pachalski, M.D., M.B., M. Kuzak Pachalska, Ph.D., C.C.C. and T. MEKaRSKI, MR.

Institute of Motor Rehabilitation at the Academy of Physical Education, Cracow, Poland.

IN the region of Cracow 50 paraplegics are under constant care of the Polish Society for Combating and Preventing Disability. The aim of social rehabilitation of paraplegics is to adapt them to the requirements of everyday life, and this is usually possible in Poland.

Twenty-three patients participated in light athletics and swimming (Group A). Twenty-seven paraplegics did not take part in sport and were found to be less physically proficient (Group B). Considering these two categories:

(I) Age of patients

Those in Group A were younger than those in Group B.

(2) Age when became paraplegic

Before the age of 20 years: Group $A=2$ I; Group B $=2$.

(3) Sex of patients

Group A: I 5 males, 8 females;

Group B: I 7 males, Io females.

(4) Martial status

Group A: 6 married

Group B: 6 married.

(5) Education

Primary

Prof essional

Incomplete secondary

Secondary

Incomplete university

University

No information

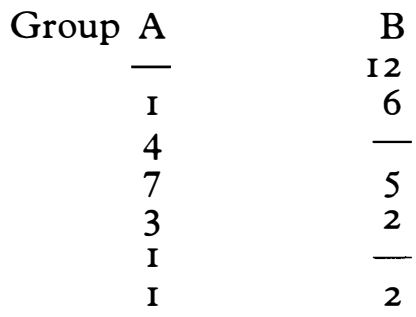

(6) Professional Work

The success of rehabilitation of those with paraplegia is the ability to undertake work, and is the aim of all rehabilitation activities in our country. Economic independence is a necessary condition for participation in normal life.

\footnotetext{
* Summary of Paper read at the Meeting of the International Medical Society of Paraplegia, Stoke Mandeville Hospital, England, July I98I.
} 
Full time work

Group A

B

Half time work

Preparing for work

Prof essional school

Studying

Receiving a pension

$\begin{array}{lr}5 & 13 \\ 2 & - \\ - & \text { I }\end{array}$

(7) The monthly income of patients

The income of patients in Group ' $A$ ' is over $2000 \mathrm{zl}$. In the majority of cases, 73.9 per cent it is over $3000 \mathrm{zl}$. In group 'B' 77.8 per cent patients have less than $3000 \mathrm{zl}$ and among them some receive less than $\mathrm{I} 5000 \mathrm{zl}: \mathbf{2 2} \cdot \mathbf{2}$ per cent of all patients in this group.

The financial situation of patients in Group A is much better than those in group $B$ among whom $22 \cdot 2$ per cent do not receive a 'social minimum'. It is stressed that all the examined paraplegics reviewed are at an age that they can either work or learn to work.

(8) Occupation

Manual work

Non-manual work

Student

Pupil

Others (have not learned to work)

$\begin{array}{rr}\text { A } & \text { B } \\ \text { I } 4 & \text { I } \\ 4 & \text { I } \\ 3 & \text { I } \\ \text { I } & \text { I }\end{array}$

(9) Living standard
Group A:
I 4
Group B: $\quad$ I 5 .

Thus, one requirement of rehabilitation is not fulfilled, that each paraplegic should have his own room. This situation can be partially explained by the very difficult housing problem in the region of Cracow.

(IO) Means of transport

All used a wheelchair as the basic means of transportation, and in addition, I I patients in Group A had a motor car, and eight in Group B.

Sixteen patients in Group A were unable to drive, and I9 in Group B.

(I I) Adaptation to the environment

All patients in Group A and the majority in Group B work in co-operatives, so they have managed to solve the problem of transport. In Group A only one person could not go out without assistance.

(12) Frequency of social contacts

This was quite frequent in 16 patients in Group A; but zero in Group B. 
(13) Vacation

Going abroad is very popular among patients in Group A. They go mainly to sports competitions; five took part on ten occasions, the others on several occasions. In Group B, I8 persons have not travelled abroad, the others have been abroad one to three times.

(14) Self-dependence (patients evaluation)

In Group A all the patients considered themselves to be self dependent.

In Group B 20 of the 27 persons considered that they were self dependent. In Group A only 4 persons expected other people to help them, mainly in carrying their wheelchair.

In Group B, I8 persons expected help in such situations as shopping, cleaning, climbing stairs etc. 